$6{ }^{1}$ Department of Psychiatry, University of Milan, Fondazione IRCCS Ca' Granda Policlinico, Milan, Italy

$7 \quad{ }^{2}$ Department of Psychiatry and Behavioral Sciences, Bipolar Disorders Clinic, Stanford Medical School, Stanford University, California, USA

\author{
Bernardo Dell'Osso, ',2*Matteo Vismara, ' Cristina Dobrea, 'Laura Cremaschi, ' \\ Benedetta Grancini, ' Chiara Arici, 'Beatrice Benatti, 'Massimiliano Buoli, \\ Terence A. Ketter, ${ }^{2}$ and A. Carlo Altamura'
}

\title{
Clinical characterization of Italian suicide attempters with bipolar disorder
}

Introduction. Bipolar disorder (BD) is a chronic, highly disabling condition associated with psychiatric/medical comorbidity and substantive morbidity, mortality, and suicide risks. In prior reports, varying parameters have been associated with suicide risk.

Objectives. To evaluate sociodemographic and clinical variables characterizing Italian individuals with BD with versus without prior suicide attempt (PSA).

Methods. A sample of 362 Italian patients categorized as BD according to the Diagnostic and Statistical Manual of Mental Disorders, Fourth Edition, Text Revision (DSM IV-TR) was assessed and divided in 2 subgroups: with and without PSA. Sociodemographic and clinical variables were compared between prior attempters and non-attempters using corrected multivariate analysis of variance (MANOVA).

Results. More than one-fourth of BD patients $(26.2 \%)$ had a PSA, with approximately one-third $(31 \%)$ of these having $>1$ PSA. Depressive polarity at onset, higher number of psychiatric hospitalizations, comorbid alcohol abuse, comorbid eating disorders, and psychiatric poly-comorbidity were significantly more frequent $(p<.05)$ in patients with versus without PSA. Additionally, treatment with lithium, polypharmacotherapy ( $\geq 4$ current drugs) and previous psychosocial rehabilitation were significantly more often present in patients with versus without PSA.

Conclusions. We found several clinical variables associated with PSA in BD patients. Even though these retrospective findings did not address causality, they could be clinically relevant to better understanding suicidal behavior in BD and adopting proper strategies to prevent suicide in higher risk patients.

Received 1 February 2017; Accepted 4 April 2017

Key words: Bipolar disorder, clinical characterization, pharmacological treatment, prior suicide attempt, suicide.

\section{Introduction}

Bipolar disorder (BD) includes different chronic, often comorbid, and highly disabling conditions that are responsible, in the most severe cases, for a high burden of morbidity and mortality, often related to suicidal behavior. In this respect, the International Society for Bipolar Disorder Task Force, in a recent systematic review of studies from 1980 to 2014, reported a pooled suicide rate for bipolar patients of 164 per 100.000

* Address for correspondence: Dr Bernardo Dell'Osso, Department of Psychiatry, University of Milan, Fondazione IRCCS Ca' Granda Policlinico, Via F. Sforza, 35, 20122 Milan, Italy.

(Email: bernardo.dellosso@unimi.it) person-years, ${ }^{1}$ a rate 10 - to 30 -fold higher compared to the general population. ${ }^{2}$

In a previous study of 176.347 patients with varying psychiatric diseases who were referred for secondary mental health services, the absolute risk of suicide in BD patients was approximately $8 \%$ for men and $5 \%$ for women over a median of 18 years of follow-up. ${ }^{3}$

With respect to suicide attempts in $\mathrm{BD}$, studies have reported that $20 \%-50 \%$ of patients suffering from BD had a prior suicide attempt (PSA), ${ }^{4-7}$ with risk being higher in younger patients and during the first years after diagnosis. ${ }^{8}$

Recognizing risk factors associated with suicide and, therefore, being able to adopt proper strategies to 


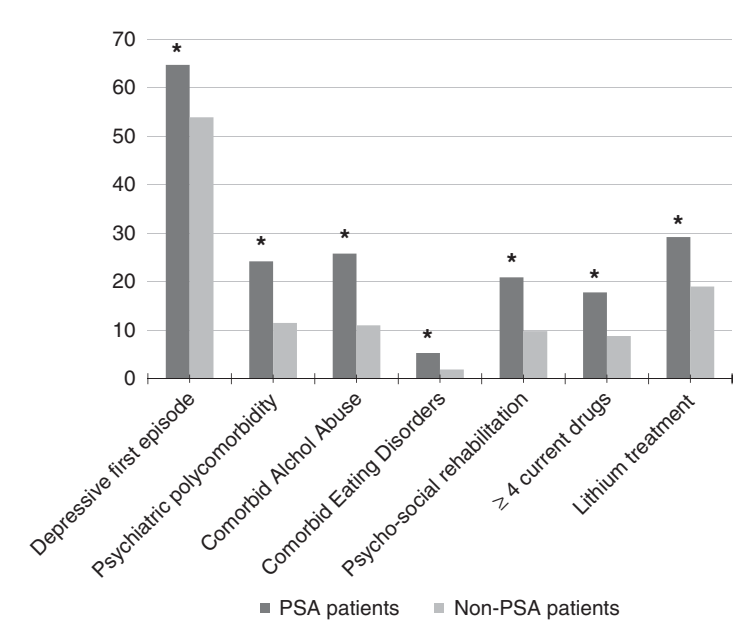

FIGURE 1. Continuous clinical variables found to be statistically different between patients with and without prior suicide attempt (PSA). All data are expressed in percentage. ${ }^{*} p<.05$.

predict it are of particular importance for clinicians involved in the management of bipolar patients. In a recent report from our group, BD patients with depressive versus elevated polarity at onset more frequently had PSA. ${ }^{9}$ Several additional risk factors have been previously linked to suicide in the bipolar population, but PSA in particular is consistently reported to be one of the main risk factors implicated in suicidal behavior. ${ }^{10-12}$ Of note, death by suicide was predicted by PSA in at least $50 \%$ of the cases. ${ }^{13}$

Other factors associated with PSA in BD patients include early age at onset ${ }^{13-16}$; long duration of illness ${ }^{15,16}$; long duration of untreated illness (DUI) ${ }^{16,17}$; positive family history for suicide ${ }^{14,18-20}$; higher lifetime number of hospitalizations ${ }^{21}$; comorbid alcohol/substance use $^{4,15,16}$; eating, ${ }^{16}$ anxiety, ${ }^{4}$ and personality (particularly Cluster B) disorders ${ }^{20}$; presence of complex psychopharmacological therapy; and absence of treatment. ${ }^{11}$ Among sociodemographic variables, female gender ${ }^{4,15,16,22}$ and single marital status in bipolar disorder I (BD-I) patients ${ }^{23}$ were associated with PSA.

Despite the above-mentioned findings, suicidal behavior remains very difficult to predict. ${ }^{24}$ The causes are complex and multiple, and each factor adds only a small amount to overall risk, particularly in light of the correlation between genetic and environmental factors. ${ }^{25}$ Moreover, it is difficult to determine whether a single factor is associated with a higher suicidal risk per se or due to the presence of $\mathrm{BD}$, since some features of PSA among bipolar patients partially overlap with those of PSA observed in patients who suffer from other psychiatric disorders and in the general population. ${ }^{11}$

In the present study, we assessed sociodemographic and clinical variables in Italian BD patients with versus without PSA, with the aim of better characterizing suicidal behavior in the BD population.

\section{Methods}

The study included 362 bipolar patients, who were recruited at the University Department of Mental Health at the Fondazione IRCCS Ca' Granda, Ospedale Maggiore Policlinico in Milan, Italy. In order to depict a better representation of the phenomenology of Italian BD patients living in the Milan metropolitan area, patients referred by community-based psychiatric services were also included. Written informed consent was obtained from all participants, after the description of the study, in order to have their clinical charts reviewed for research purposes.

The Structured Clinical Interviews for Diagnostic and Statistical Manual of Mental Disorders, Fourth Edition, Text Revision (SCID I and II), ${ }^{26-28}$ were administered to all participants by psychiatrists or residents in psychiatry with a specific training in mood disorders in order to confirm Axis I/II diagnoses and detect any comorbid psychiatric condition(s). To increase diagnostic specificity, only individuals with BD-I or bipolar disorder II (BD-II) and not those with BD Not Otherwise Specified were included in the study sample. In case of comorbidity with another psychiatric disorder, BD had to be the primary diagnosis affecting patient's everyday functioning and being mostly responsible for its impact on quality of life and for help-seeking. Patients with evidence of mental retardation, neurological disorders, organic mental illnesses, or other disabling medical conditions were excluded.

Sociodemographic variables included age, gender, education, employment, cohabitation, and marital status. Clinical variables included: diagnosis; age at onset (AAO, ie, age of first mood episode of any polarity), with a categorical distinction between childhood/adolescent onset ( $<18$ years old) and adult onset ( $\geq 18$ years old); duration of illness; DUI; polarity of first episode [depressed or elevated (manic, hypomanic, or mixed)]; duration of most recent episode; lifetime number of psychiatric hospitalizations and involuntary commitments; presence of psychiatric disorders in the family (first- and second-degree relatives); presence of lifetime psychosis; current subthreshold symptoms; stressful life events before onset; cross-sectional and lifetime psychiatric and medical comorbidity; and history of psychosocial rehabilitation (ie, community-based interventions aimed at improving patients' social/working skills, reducing functional disability, and improving quality of life). ${ }^{29}$ In order to evaluate patients' current level of global functioning, the Global Assessment of Functioning $(\mathrm{GAF})^{30}$ was administered after the resolution of the last syndromic mood episode in order to exclude potential current mood state-related bias.

Data related to lifetime number, methods used (eg, selfpoisoning, cutting, jumping, or others), and severity of PSA 


\begin{tabular}{|c|c|c|c|}
\hline Variables & Total sample & PSA patients & Non-PSA patients \\
\hline $\mathrm{N}(\%)$ & $362(100)$ & $95(26.2)$ & $267(73.8)$ \\
\hline Age (years, mean $\pm S D$ ) & $48.6 \pm 14.4$ & $49.7 \pm 13.8$ & $48.2 \pm 14.5$ \\
\hline \multicolumn{4}{|l|}{ Gender (\%) } \\
\hline Male & 47.5 & 43.2 & 48.7 \\
\hline Female & 52.5 & 56.8 & 51.3 \\
\hline \multicolumn{4}{|l|}{ Education (\%) } \\
\hline Secondary school & 16.9 & 20.9 & 15.6 \\
\hline High-school & 51.3 & 48.4 & 52.9 \\
\hline University & 29.1 & 27.5 & 29.1 \\
\hline \multicolumn{4}{|l|}{ Employment (\%) } \\
\hline Employed & 48.7 & 48.4 & 49.0 \\
\hline Unemployed & 37.8 & 39.6 & 37.3 \\
\hline Retired & 13.5 & 12.1 & 13.7 \\
\hline \multicolumn{4}{|l|}{ Co-habitation (\%) } \\
\hline Family & 45.7 & 46.1 & 45.8 \\
\hline Family of origin & 24.7 & 22.5 & 25.6 \\
\hline Alone & 22.9 & 22.5 & 22.7 \\
\hline Other & 6.7 & 9.0 & 5.9 \\
\hline \multicolumn{4}{|l|}{ Marital status (\%) } \\
\hline Single & 43.0 & 38.0 & 45.2 \\
\hline Partner & 42.1 & 41.3 & 41.9 \\
\hline Divorced & 12.3 & 16.3 & 10.9 \\
\hline $\begin{array}{l}\text { Values for categorica } \\
\text { and mean } \pm S D \text {, respect }\end{array}$ & nd continuous & & sed in percentages \\
\hline
\end{tabular}

were collected. PSAs were considered clinically serious if a medical or surgical intervention was necessary and if PSAs would have been potentially lethal without a proper medical intervention; otherwise PSAs were considered mild.

Current pharmacological treatment, if any, was recorded, and we considered the use of lithium, mood stabilizers, antipsychotics, and antidepressants as primary and adequate treatment for $\mathrm{BD}$, either in mono- or polytherapy. In addition, the presence of polypharmacotherapy, defined by current use of $>3$ psychotropic compounds, was assessed.

All patients were then divided into 2 groups according to the lifetime occurrence of at least 1 PSA: PSA patients and non-PSA patients.

Statistical analyses were performed using the Statistical Package for the Social Sciences (SPSS), version 22. Multivariate analysis of variance (MANOVA) was used to compare the 2 subgroups for continuous variables. The MANOVA model proved to be valid (Wilks lambda test, $\mathrm{p}<.001)$. Chi-square tests were used to compare categorical variables, with Bonferroni post-hoc analysis. A 2-tailed significance threshold was set at $\mathrm{p}<.05$.

\section{Results}

Sociodemographic and clinical variables of the entire sample and related subgroups are shown in Tables 1 and 2 , respectively.

TABLE 1. Socio-demographic variables of the total sample and
TABLE 2. Clinical variables of the total sample and patients with and without prior suicide attempt (PSA)

$\begin{array}{cccc} & \text { Total } & \text { PSA } & \text { Non-PSA } \\ \text { Variables } & \text { sample } & \text { patients } & \text { patients }\end{array}$

Diagnosis

BD I

BD ॥

Age at onset (years, mean $\pm S D$ )

$<18$ years

$\geq 18$ years

Duration of illness (months,

mean \pm SD)

Duration of untreated illness

(months, mean \pm SD)

Family history of psychiatric disorder (\%)

Polarity of first episode

Depressive first episode (\%)

Elevated first episode (\%)

Duration of most recent episode (days, mean \pm SD)

Psychiatric hospitalizations (lifetime \#, mean \pm SD)

Involuntary commitments

(lifetime \#, mean \pm SD)

Psychosis (lifetime, \%)

Subthreshold symptoms (lifetime, \%)

Stressful life events (lifetime, \%)

Psychiatric comorbidity (\%)

Any

Generalized anxiety disorde

Panic disorder

Any anxiety disorder

Obsessive compulsive disorder

Personality disorder

Alcohol abuse

Substance use disorder

Eating disorder

Psychiatric poly-comorbidity

Medical comorbidity (lifetime, \%)

Psychosocial rehabilitation (lifetime, \%)

Global Assessment of Functioning

(current, mean $\pm \mathrm{SD}$ )

Current treatment (\%)

Mood stabilizers

Lithium

Antipsychotics

Mood stabilizers + antipsychotics

\section{3}

25.7

75.8

74.0

$28.7 \pm 11.4 \quad 27.3 \pm 10.1 \quad 29.2 \pm 11.8$

$\begin{array}{lll}12.8 & 15.1 & 11.7\end{array}$

$87.2 \quad 84.9 \quad 88.3$

$241.8 \pm 155.6 \quad 274 \pm 156.3 \quad 230.1 \pm 154$.

$58 \pm 101.2 \quad 60.8 \pm 99.6 \quad 55.9 \pm 100.9$

$$
\begin{array}{ccc}
65.6 & 67.0 & 64.9 \\
57.6 & \mathbf{6 7 . 4 *} & 53.9 \\
42.4 & 32.6 & \mathbf{4 6 . 1 ^ { * }} \\
40.6 \pm 54.9 & 42.0 \pm 58.5 & 40.3 \pm 54.0 \\
3.1 \pm 5.1 & \mathbf{5 . 1 \pm 8 . 4 ^ { * * }} & 2.3 \pm 2.7 \\
& & \\
0.6 \pm 1.4 & 0.5 \pm 1.4 & 0.6 \pm 1.4
\end{array}
$$

$\begin{array}{lll}57.5 & 56.4 & 58.3\end{array}$

$\begin{array}{lll}47.0 & 49.4 & 46.6\end{array}$

$58.3 \quad 59.0 \quad 58.1$

$\begin{array}{lll}47.4 & 48.4 & 47.9\end{array}$

$\begin{array}{lll}19.6 & 18.3 & 20.2\end{array}$

$\begin{array}{lll}6.5 & 3.2 & 7.8\end{array}$

$29.1 \quad 25.5 \quad 30.5$

$\begin{array}{lll}1.4 & 2.2 & 1.2\end{array}$

$\begin{array}{lll}5.1 & 7.5 & 4.3\end{array}$

$14.8 \quad 25.8^{*} \quad 11.0$

$17.1 \quad 19.1 \quad 16.5$

$\begin{array}{lll}3.1 & 5.3^{*} & 1.9\end{array}$

$14.7 \quad 24.2^{*} \quad 11.5$

$\begin{array}{lll}48.3 & 57.9 & 44.4\end{array}$

$12.7 \quad 20.9 * \quad 9.8$

$\begin{array}{ccc}12.7 & 20.9 * & 9.8 \\ 65.3 \pm 14 & 62.5 \pm 13.7 & 66.2 \pm 14.0\end{array}$

Antidepressants

Psychotropic drugs

$0-3$ drugs

$\geq 4$ drugs

SA methods (\%)

Self-poisoning

Cutting

Jumping

SA gravity (\%)

Mild

Serious

$\begin{array}{rrr}73.2 & 75.6 & 72.1 \\ 21.6 & 29.2^{*} & 19.0 \\ 82.1 & 83.5 & 82.3 \\ 59.8 & 63.3 & 59.0 \\ 35.0 & 30.5 & 36.0 \\ & & \\ 88.9 & 82.2 & 91.2^{*} \\ 11.1 & 17.8^{*} & 8.8 \\ & & \\ 13.9 & 60.0 & 0.0 \\ 4.1 & 17.5 & 0.0 \\ 3.7 & 16.0 & 0.0 \\ & & \\ 9.4 & 42.7 & 0.0 \\ 12.6 & 57.3 & 0.0\end{array}$

Values for categorical and continuous variables are expressed in percentages and mean $\pm S D$, respectively. Boldface indicates parameters with significant differences between the 2 subgroups. ${ }^{*} p<.05,{ }^{* *} p<.001$. 
In our sample, 95 patients had PSAs, slightly above onequarter of the total sample $(26.2 \%)$, with all patients having survived their PSA. Reported methods were self-poisoning $(60 \%)$, followed by cutting (17.5\%), jumping (16\%), and other modalities (eg, hanging, gas inhalation, voluntary car accident, frostbite, electrocution). More than half of patients with PSA had at least 1 serious PSA (57.3\%). Patients with more than 1 PSA comprised $7.9 \%$ of the entire sample, and almost one-third (31.8\%) of the PSA subgroup.

The PSA and non-PSA subgroups were similar in respect to sociodemographic variables, with no statistically significant difference in terms of gender, education, marital status, employment, or cohabitation.

With respect to clinical variables (Figure 1), patients with versus without PSA more frequently had depressive polarity at their first mood episode $(67.4$ vs $53.9 \%$; $\chi^{2}=8.5, \mathrm{df}=3 ; \mathrm{p}=.03$ ).

The number of lifetime psychiatric hospitalizations was higher in patients with versus without PSA $(5.1 \pm 8.4$ vs $2.3 \pm 2.7 ; \mathrm{F}=78.8, \mathrm{p}<.001)$. However, these subgroups did not have any statistically significant difference in terms of involuntary commitment.

The PSA and non-PSA subgroups did not show a statistically significant difference regarding general psychiatric comorbidity, even though PSA patients reported to suffer more frequently from psychiatric poly-comorbidity $\left(24.2 \%\right.$ vs $11.5 \% ; \chi^{2}=8.6, \mathrm{df}=1$; $\mathrm{p}=.004)$. Additionally, the PSA group more frequently reported comorbid alcohol abuse disorder, either current or lifetime $\left(25.8 \%\right.$ vs $11.0 \% ; \quad \chi^{2}=11.4, \quad \mathrm{df}=1$; $\mathrm{p}=.001)$, and eating disorders $(5.3 \%$ vs $1.9 \% ; \mathrm{p}<.05)$.

Focusing on psychiatric treatment, polypharmacotherapy was more commonly present in PSA vs nonPSA patients $\left(17.8 \%\right.$ vs $\left.8.8 \% ; \chi^{2}=5.4, \mathrm{df}=1 ; \mathrm{p}=.03\right)$. Moreover, the use of lithium as mood stabilizer was higher in PSA compared with non-PSA patients (29.2 vs $19.0 ; \chi^{2}=4.0, \mathrm{df}=1 ; \mathrm{p}=.05$ ). There was no other statistically significant pharmacotherapy difference in patients with versus without PSA.

Finally, patients with versus without PSA more frequently needed, in their lifetime, psychosocial rehabilitation $\left(20.9 \%\right.$ vs $\left.9.8 \% ; \chi^{2}=7.3, \mathrm{df}=1 ; \mathrm{p}=.007\right)$.

In contrast, patients with versus without PSA did not significantly differ in terms of BD subtype, age at onset, duration of illness, DUI, psychiatric family history, duration of last mood episode, stressful life events, subthreshold symptoms, or GAF score.

\section{Discussion}

In our sample, more than 1 in 4 BD patients $(26.2 \%)$ had PSA. This finding is consistent with prior reports ${ }^{1,31,32}$ and highlights the strong association between BD and PSA. Some studies, such as the Systematic Treatment Enhancement Program for Bipolar Disorder (STEP-BD)
(PSA prevalence of $36 \%)^{13}$ and a previous collaborative investigation of our group, which was conducted on an American sample (PSA rate of $30 \%),{ }^{6}$ showed higher frequencies. On the other hand, a lower PSA frequency emerged in some studies, such as a Korean investigation that reported a PSA rate of $13.1 \%$ in BD inpatients. ${ }^{33}$ Novick et $\mathrm{al}^{10}$ conducted a meta-analysis of 24 prospective studies with a follow-up period ranging from 18 months to 44 years, and observed a mean suicide attempt frequency of $23.8 \%$ in BD-I and $19.8 \%$ in BD-II patients. In our sample, a similar rate of PSA in BD-I and BD-II subjects emerged, as previously reported in collaborative studies of our group ${ }^{6,7,34}$ and in other reports. ${ }^{4,10,13,20,31,35-40}$ However, some studies have variably reported PSA rates in relation to BD subtype, with a higher PSA rate in BD-I ${ }^{41-43}$ or BD-II. ${ }^{33,44}$

According to the above-mentioned results, selfpoisoning (ie, overdose) represented the most common PSA method (60\%), which is consistent with most prior studies. For instance, Schaffer et al, ${ }^{1}$ in the International Society for Bipolar Disorders (ISBD) Task Force report, found self-poisoning being used in an overall wide range (29.8\%-80.1\%), with studies documenting lower rates in Asians ${ }^{33,45}$ and higher rates in patients from other countries. ${ }^{46,47}$ According to the same authors, the next most used PSA methods were as follows: cutting (5.6\%-22.7\%), hanging $(0.7 \%-26.3 \%)$, jumping (4.8\%-13.2\%), drowning $(0.2 \%-16.7 \%)$, gas inhalation $(2.8 \%-5.7 \%)$, shooting $(1.4 \%-4.2 \%)$, self-immolation $(1.3 \%-2.1 \%)$, and intentional car accident $(1.4 \%) .{ }^{1}$ In our study, cutting and jumping were the second and third most used PSA methods, with rates of $17.5 \%$ and $16 \%$, respectively. Comparing these results with literature data, our observed rates of cutting seemed to be consistent with available studies, while rates of jumping were overrepresented.

In our study, approximately one-third (31.8\%) of patients with PSA had more than 1 PSA. This result is similar to the STEP-BD report, ${ }^{13}$ but lower compared to the study by Michaelis et al, ${ }^{48}$ which reported two-thirds of PSA patients having multiple PSAs.

Over the past several years, several clinical characteristics have been extensively studied to find an association between BD and suicidal behavior. For instance, prior studies found depressive polarity at first mood episode was more frequently related to PSA, ${ }^{15,16,20,22,23,33,37,40}$ and this finding was confirmed in the present sample. In addition, in a recent study from our group that analyzed the same sample divided into 2 subgroups in relation to the polarity at onset, it emerged that bipolar patients with a depressive versus elevated polarity at onset had a 2-fold risk of PSA. ${ }^{9}$ On the other hand, patients with a manic episode at onset were found to show a lower risk in other studies, ${ }^{36,49,50}$ even though they more frequently adopted violent PSA methods. ${ }^{51}$ 
To our knowledge, this is the first study that has specifically analyzed the burden of psychiatric polycomorbidity in relation to PSA, and this variable emerged to be more frequently encountered in patients with PSA. Such patients might suffer from a more severe form of BD due to higher comorbidity burden, which could contribute to increasing the PSA risk. Focusing on specific comorbidities, in fact, higher PSA risk has been previously associated with current and lifetime substance use disorder. ${ }^{4,23,37,40,51,52}$ One report linked PSA risk with alcohol or substance abuse only. ${ }^{47}$ In this respect, a statistically significant correlation between PSA and alcohol use disorder (but not substance use disorder) emerged in our sample.

Anxiety disorder comorbidity has been strongly associated with higher PSA risk. ${ }^{4,20,32,51,53}$ Nonetheless, this was not confirmed in our report; our sample showed similar rates between PSA and non-PSA patients, or approximately 1 out of 2 patients.

Confirming what emerged in the present sample, previous studies highlighted a correlation between eating disorder comorbidity and PSA in BD. ${ }^{12,16,53}$ Indeed, eating disorders represent a risk factor per se for suicidal behaviors, ${ }^{54}$ with the BD comorbidity possibly increasing this risk.

One important goal of proper pharmacological treatments is to prevent suicide. ${ }^{55}$ In our study, patients with versus without PSA were more frequently treated with lithium. This finding may seem to be in contrast with the compound's well established protective effect toward suicidal behavior. ${ }^{56-58}$ The result, however, should be interpreted as a consequence of the retrospective nature of the study, and, therefore, lithium treatment could have been prescribed following a PSA as a preventive strategy.

In relation to antidepressant drugs, our study did not show any difference between patients with versus without PSA, in contrast with some prior reports, where PSA occurred more often in bipolar patients taking versus not taking antidepressants. ${ }^{16,44}$

Our findings showed that complex pharmacotherapy (>3 drugs/day at assessment) was more commonly received by PSA patients, as reported in a recent study. ${ }^{16}$ This result might depend on the more frequent polycomorbidity observed in such patients. Additionally, the occurrence of a PSA might have been the reason to add another pharmacological treatment (eg, lithium).

In our sample, patients with versus without PSA reported a higher lifetime number of psychiatric hospitalizations. Prior studies are discordant on this topic, with some authors confirming ${ }^{2}$ and others not confirming $^{16,21}$ our finding. The higher occurrence of psychiatric hospitalizations might be explained by the association between predominant depressive polarity and PSA, which was not evident in our sample but has been reported in other studies, ${ }^{59-61}$ in light of the reported correlation between predominant depressive polarity and increased number of hospitalizations. ${ }^{62}$

To our knowledge, ours is the first report to show that patients with versus without PSA more often had psychosocial rehabilitation. Since no difference between PSA versus non-PSA patients in relation to current subthreshold symptoms or GAF score emerged in our sample, a PSA might be considered an independent clinical reason to suggest the initiation of a psychosocial rehabilitation program. Alternatively, PSA patients might have a higher need for rehabilitation in light of the greater disease burden (eg, due to the more frequently associated comorbidities, as observed in our sample).

In our sample, other clinical variables did not show any statistically significant difference between patients with versus without PSA, in contrast with prior reports, such as, for instance, an earlier AAO, ${ }^{12-14,16,18,33,63}$ a longer duration of disease, ${ }^{15,16}$ and a longer DUI, ${ }^{17,64}$ which were more commonly related to patients with PSA.

Our PSA and non-PSA subgroups did not have any statistically significant difference in sociodemographic variables. Prior studies found that PSA patients were more frequently of female gender, ${ }^{12,15,16,22,42}$ even though death by suicide was associated with male gender $^{3,5}$ and use of more violent methods. ${ }^{39}$

In the interpretation of the aforementioned results, the following methodological limitations should be taken into consideration. First, due the nature of the study, all collected variables were obtained retrospectively and, therefore, are susceptible to recall bias. Additionally, the severity of suicide attempts was assessed by clinicians through a descriptive criterion, and not through a specific standardized scale. Moreover, the nature of episodes in which PSA occurred was not collected for all patients. A further limitation is that the present study was based on a cross-sectional analysis, with a longitudinal assessment being potentially more beneficial for evaluation of further suicidal behaviors. In relation to statistical analysis, we did not perform a multivariate analysis of covariance because clinically relevant variables, such as BD subtypes, age at onset, and DUI, did not show any difference between PSA subgroups. Finally, our sample mostly attended a university clinic, and this may limit the generalizability of our findings due to referral bias. Therefore, further investigation with a wider sample size is deemed necessary to confirm our results.

\section{Disclosures}

Bernardo Dell'Osso, Matteo Vismara, Cristina Dobrea, Laura Cremaschi, Benedetta Grancini, Chiara Arici, Beatrice Benatti, Massimiliano Buoli, and A. Carlo Altamura do not have anything to disclose. Terence 
386 Ketter reports personal fees from Acadia Pharmaceuti387 cals, personal fees from Allergan Pharmaceuticals, 388 personal fees from Depomed, personal fees from 389 Genentech, personal fees and other from Janssen 390 Pharmaceuticals, grants and personal fees from Merck 391 \& Co., Inc., personal fees from Myriad Genetic Labora392 tories, Inc., personal fees from Navigen, personal fees 393 from ProPhase, grants and personal fees from Sunovion 394 Pharmaceuticals, grants and personal fees from Teva 395 Pharmaceuticals, personal fees from GlaxoSmithKline, 396 personal fees from Pfizer, Inc., and personal fees from 397 American Psychiatric Publishing, Inc., outside the 398 submitted work.

\section{REFERENCES:}

1. Schaffer A, Isometsä ET, Tondo L, et al. Epidemiology, neurobiology and pharmacological interventions related to suicide deaths and suicide attempts in bipolar disorder: Part I of a report of the International Society for Bipolar Disorders Task Force on Suicide in Bipolar Disorder. Aust N Z J Psychiatry. 2015; 49(9): 785-802.

2. Pompili M, Gonda X, Serafini G, et al. Epidemiology of suicide in bipolar disorders: a systematic review of the literature. Bipolar Disord. 2013; 15(5): 457-490.

3. Nordentoft M, Mortensen PB, Pedersen CB. Absolute risk of suicide after first hospital contact in mental disorder. Arch Gen Psychiatry. $2011 ; \mathbf{6 8}(10)$ : 1058-1064.

4. Simon GE, Hunkeler E, Fireman B, Lee JY, Savarino J. Risk of suicide attempt and suicide death in patients treated for bipolar disorder. Bipolar Disord. 2007; 9(5): 526-530.

5. Schaffer A, Sinyor M, Reis C, Goldstein BI, Levitt AJ. Suicide in bipolar disorder: characteristics and subgroups. Bipolar Disord. 2014; 16(7): 732-740.

6. Dell'Osso B, Holtzman JN, Goffin KC, et al. American tertiary clinicreferred bipolar II disorder compared to bipolar I disorder: more severe in multiple ways, but less severe in a few other ways. J Affect Disord. 2015; 188: 257-262.

7. Dell'Osso B, Dobrea C, Cremaschi L, et al. Italian bipolar II vs I patients have better individual functioning, in spite of overallsimilar illness severity. CNS Spectr. In press. DOI: 10.1017/S1092852915000887.

8. Jamison KR. Suicide and bipolar disorder. J Clin Psychiatry. 2000; 61(Suppl 9): 47-51.

9. Undurraga J, Baldessarini RJ, Valenti M, Pacchiarotti I, Vieta E. Suicidal risk factors in bipolar I and II disorder patients. J Clin Psychiatry. 2012; 73(6): 778-782.

10. Novick DM, Swartz HA, Frank E. Suicide attempts in bipolar I and bipolar II disorder: a review and meta-analysis of the evidence. Bipolar Disord. 2010; 12(1): 1-9.

11. Schaffer A, Isometsä ET, Azorin J-M, et al. A review of factors associated with greater likelihood of suicide attempts and suicide deaths in bipolar disorder: Part II of a report of the International Society for Bipolar Disorders Task Force on Suicide in Bipolar Disorder. Aust N Z J Psychiatry. 2015; 49(11): 1006-1020.

12. Tidemalm D, Haglund A, Karanti A, Landén M, Runeson B. Attempted suicide in bipolar disorder: risk factors in a cohort of 6086 patients. PLoS One. 2014; 9(4): e94097.

13. Dennehy EB, Marangell LB, Allen MH, Chessick C, Wisniewski SR, Thase ME. Suicide and suicide attempts in the Systematic Treatment Enhancement Program for Bipolar Disorder (STEP-BD). J Affect Disord. 2011; 133(3): 423-427.

14. Antypa N, Souery D, Tomasini M, et al. Clinical, psychological and environmental predictors of prospective suicide events in patients with bipolar disorder. J Psychiatr Res. 2013; 47(11): 1800-1808.

15. Bellivier F, Yon L, Luquiens A, et al. Suicidal attempts in bipolar disorder: results from an observational study (EMBLEM). Bipolar Disord. 2011; 13(4): 377-386.

16. Goffin KC, Dell'Osso B, Miller S, et al. Different characteristics associated with suicide attempts among bipolar I versus bipolar II disorder patients. J Psychiatr Res. 2016; 76: 94-100.

17. Altamura AC, Dell'Osso B, Berlin HA, Buoli M, Bassetti R, Mundo E. Duration of untreated illness and suicide in bipolar disorder: a naturalistic study. Eur Arch Psychiatry Clin Neurosci. 2010; 260(5): 385-391.

18. Parmentier C, Etain B, Yon L, et al. Clinical and dimensional characteristics of euthymic bipolar patients with or without suicidal behavior. Eur Psychiatry. 2012; 27(8): 570-576.

19. Leverich GS, Altshuler LL, Frye MA, et al. Factors associated with suicide attempts in 648 patients with bipolar disorder in the Stanley Foundation Bipolar Network. J Clin Psychiatry. 2003; 64(5): 506-515.

20. Sánchez-Gistau V, Colom F, Mané A, Romero S, Sugranyes G, Vieta E. Atypical depression is associated with suicide attempt in bipolar disorder. Acta Psychiatr Scand. 2009; 120(1): 30-36.

21. Jiménez E, Arias B, Mitjans M, et al. Clinical features, impulsivity, temperament and functioning and their role in suicidality in patients with bipolar disorder. Acta Psychiatr Scand. 2016; 133(4): 266-276.

22. Undurraga J, Baldessarini RJ, Valenti M, Pacchiarotti I, Vieta E. Suicidal risk factors in bipolar I and II disorder patients. J Clin Psychiatry. 2012; 73(6): 778-782.

23. Azorin JM, Kaladjian A, Adida M, et al. Risk factors associated with lifetime suicide attempts in bipolar I patients: findings from a French National Cohort. Compr Psychiatry. 2009; 50(2): 115-120.

24. O'Connor E, Gaynes BN, Burda BU, Soh C, Whitlock EP. Screening for and treatment of suicide risk relevant to primary care: a systematic review for the U.S. Preventive Services Task Force. Ann Intern Med. 2013; 158(10): 741-754.

25. Neves FS, Malloy-Diniz LF, Corrêa H. Suicidal behavior in bipolar disorder: what is the influence of psychiatric comorbidities? J Clin Psychiatry. 2009; 70(1): 13-18.

26. First M, Gibbon M, Spitzer R, Williams J, Benjamin L. Structured Clinical Interview for DSM-IV Axis II Personality Disorders (SCID-II). Washington, DC: American Psychiatric Press; 1997.

27. First M, Spitzer R, Gibbon M, Williams J. Structured Clinical Interview for DSM-IV-TR Axis I Disorders, Research Version, Patient Edition (SCID-I/P). New York: Biometrics Research, New York State Psychiatric Institute; 2002.

28. American Psychiatric Association. Diagnostic and Statistical Manual of Mental Disorders. 4th ed, text rev. Washington, DC: American Psychiatric Association; 2000.

29. Barbato A. Psychosocial rehabilitation and severe mental disorders: a public health approach. World Psychiatry. 2006; 5(3): 162-163.

30. Hall RC. Global assessment of functioning. A modified scale. Psychosomatics. 1995; 36(3): 267-275.

31. Merikangas KR, Jin R, He J-P, et al. Prevalence and correlates of bipolar spectrum disorder in the World Mental Health Survey Initiative. Arch Gen Psychiatry. 2011; 68(3): 241-251.

32. Sala R, Goldstein BI, Morcillo C, Liu S-M, Castellanos M, Blanco C. Course of comorbid anxiety disorders among adults with bipolar disorder in the U.S. population. J Psychiatr Res. 2012; 46(7): 865-872.

33. Ryu V, Jon D-I, Cho HS, et al. Initial depressive episodes affect the risk of suicide attempts in Korean patients with bipolar disorder. Yonsei Med J. 2010; 51(5): 641-647.

34. Dell'Osso B, Shah S, Do D, et al. American tertiary clinic-referred bipolar II disorder versus bipolar I disorder associated with hastened depressive recurrence. Int J Bipolar Disord. 2017; 5: 2. 
35. Chen L, Liu Y-H, Zheng Q-W, et al. Suicide risk in major affective disorder: results from a national survey in China. J Affect Disord. 2014; 155: 174-179.

36. Dalton EJ, Cate-Carter TD, Mundo E, Parikh S V, Kennedy JL. Suicide risk in bipolar patients: the role of co-morbid substance use disorders. Bipolar Disord. 2003; 5(1): 58-61.

37. Finseth PI, Morken G, Andreassen OA, Malt UF, Vaaler AE. Risk factors related to lifetime suicide attempts in acutely admitted bipolar disorder inpatients. Bipolar Disord. 2012; 14(7): 727-734.

38. Post RM, Denicoff KD, Leverich GS, et al. Morbidity in 258 bipolar outpatients followed for 1 year with daily prospective ratings on the NIMH life chart method. J Clin Psychiatry. 2003; 64(6): 680-690.

39. Perroud N, Baud P, Preisig M, et al. Social phobia is associated with suicide attempt history in bipolar inpatients. Bipolar Disord. 2007; 9(7): 713-721.

40. Valtonen HM, Suominen K, Mantere O, Leppämäki S, Arvilommi P, Isometsä ET. Prospective study of risk factors for attempted suicide among patients with bipolar disorder. Bipolar Disord. 2006; 8(5 Pt 2): 576-585.

41. Parker G, Fletcher K, McCraw S, Futeran S, Hong M. Identifying antecedent and illness course variables differentiating bipolar I, bipolar II and unipolar disorders. J Affect Disord. 2013; 148(2-3): 202-209.

42. Antypa N, Souery D, Tomasini M, et al. Clinical and genetic factors associated with suicide in mood disorder patients. Eur Arch Psychiatry Clin Neurosci. 2016; 266(2): 181-193.

43. Bega S, Schaffer A, Goldstein B, Levitt A. Differentiating between bipolar disorder types I and II: results from the National Epidemiologic Survey on Alcohol and Related Conditions (NESARC). J Affect Disord. 2012; 138(1-2): 46-53.

44. Song JY, Yu HY, Kim SH, et al. Assessment of risk factors related to suicide attempts in patients with bipolar disorder. J Nerv Ment Dis. 2012; 200(11): 978-984.

45. Ruengorn C, Sanichwankul K, Niwatananun W, Mahatnirunkul S, Pumpaisalchai W, Patumanond J. A risk-scoring scheme for suicide attempts among patients with bipolar disorder in a Thai patient cohort. Psychol Res Behav Manag. 2012; 5: 37-45.

46. D'Ambrosio V, Salvi V, Bogetto F, Maina G. Serum lipids, metabolic syndrome and lifetime suicide attempts in patients with bipolar disorder. Prog Neuropsychopharmacol Biol Psychiatry. 2012; 37(1) 136-140.

47. Sublette EM, Carballo JJ, Moreno C, et al. Substance use disorders and suicide attempts in bipolar subtypes. J Psychiatr Res. 2009; 43(3): 230-238.

48. Michaelis BH, Goldberg JF, Singer TM, Garno JL, Ernst CL, Davis GP. Characteristics of first suicide attempts in single versus multiple suicide attempters with bipolar disorder. Compr Psychiatry. 2003; 44(1): 15-20.

49. Keks NA, Hill C, Sundram S, et al. Evaluation of treatment in 35 cases of bipolar suicide. Aust N Z J Psychiatry. 2009; 43(6): 503-508.
50. Valtonen HM, Suominen K, Mantere O, Leppämäki S, Arvilommi P, Isometsä E. Suicidal behaviour during different phases of bipolar disorder. J Affect Disord. 2007; 97(1-3): 101-107.

51. Neves FS, Malloy-Diniz LF, Corrêa H. Suicidal behavior in bipolar disorder: what is the influence of psychiatric comorbidities? J Clin Psychiatry. 2009; 70(1): 13-18.

52. Oquendo MA, Currier D, Liu S-M, Hasin DS, Grant BF, Blanco C. Increased risk for suicidal behavior in comorbid bipolar disorder and alcohol use disorders: results from the National Epidemiologic Survey on Alcohol and Related Conditions (NESARC). J Clin Psychiatry. 2010; 71(7): 902-909.

53. Moor S, Crowe M, Luty S, Carter J, Joyce PR. Effects of comorbidity and early age of onset in young people with bipolar disorder on self harming behaviour and suicide attempts. J Affect Disord. 2012 136(3): 1212-1215.

54. Swanson SA, Crow SJ, Le Grange D, Swendsen J, Merikangas KR. Prevalence and correlates of eating disorders in adolescents. Results from the National Comorbidity Survey Replication Adolescent Supplement. Arch Gen Psychiatry. 2011; 68(7): 714-723.

55. World Health Organization. Preventing suicide. A global imperative. WHO Press, World Health Organization; 2014. http://apps.who. int/iris/bitstream/10665/131056/1/9789241564779_eng.pdf.

56. Baldessarini RJ, Tondo L. Lithium and suicidal risk. Bipolar Disord. 2008; 10(1): 114-115.

57. Cipriani A, Pretty H, Hawton K, Geddes JR. Lithium in the prevention of suicidal behavior and all-cause mortality in patients with mood disorders: a systematic review of randomized trials. $\mathrm{Am} \mathrm{J}$ Psychiatry. 2005; 162(10): 1805-1819.

58. Cipriani A, Hawton K, Stockton S, Geddes JR. Lithium in the prevention of suicide in mood disorders: updated systematic review and meta-analysis. BMJ. 2013; 346: f3646.

59. Carvalho AF, McIntyre RS, Dimelis D, et al. Predominant polarity as a course specifier for bipolar disorder: a systematic review. J Affect Disord. 2014; 163: 56-64.

60. Colom F, Vieta E, Daban C, Pacchiarotti I, Sánchez-Moreno J. Clinical and therapeutic implications of predominant polarity in bipolar disorder. J Affect Disord. 2006; 93(1-3): 13-17.

61. Popovic D, Torrent C, Goikolea JM, et al. Clinical implications of predominant polarity and the polarity index in bipolar disorder: a naturalistic study. Acta Psychiatr Scand. 2014; 129(5): 366-374.

62. González-Pinto A, Alberich S, Barbeito S, et al. Different profile of substance abuse in relation to predominant polarity in bipolar disorder. The Vitoria long-term follow-up study. J Affect Disord. 2010; 124(3): 250-255

63. Azorin JM, Bellivier F, Kaladjian A, et al. Characteristics and profiles of bipolar I patients according to age-at-onset: findings from an admixture analysis. J Affect Disord. 2013; 150(3): 993-1000.

64. Nery-Fernandes F, Quarantini LC, Guimarães JL, et al. Is there an association between suicide attempt and delay of initiation of mood stabilizers in bipolar I disorder? J Affect Disord. 2012; 136(3): 1082-1087. 